\title{
HISTOCHEMICAL OBSERVATIONS ON THE LIPID CHANGES IN RAT CORPORA LUTEA DURING VARIOUS REPRODUCTIVE STATES AFTER TREATMENT WITH EXOGENOUS HORMONES
}

\author{
S. S. GURAYA \\ Department of Zoology, College of Basic Sciences and Humanities, \\ Punjab Agricultural University, Ludhiana, Punjab, India
}

(Received 25th Fuly 1974)

\begin{abstract}
Summary. Lipid changes were studied histochemically in rat CL during the oestrous cycle, pregnancy and lactation after treatment with oestradiol benzoate (EB), LH and prolactin. A single injection of $50 \mu \mathrm{g} \mathrm{EB}$ given on any day during the first half of the oestrous cycle, pregnancy and lactation caused a heavy accumulation of lipid droplets, which consisted mainly of cholesterol and/or its esters, triglycerides and some phospholipids. If the treatment with EB was followed by a single injection of 20 i.u. prolactin, droplet accumulation either did not occur, or was greatly reduced. During the second half of pregnancy, a massive accumulation of cholesterol- and triglyceride-positive lipid droplets occurred in the CL of untreated rats, and prolactin was equally effective in reducing, or preventing the storage of cholesterol-positive lipid droplets. Prolactin was more effective if two injections of $10 \mathrm{i} . \mathrm{u}$. were given daily after an interval of 11 to $12 \mathrm{hr}$. No appreciable lipid change in the CL was caused by injection of $100 \mu \mathrm{g} L \mathrm{H}$ on any day during the first half of the oestrous cycle and pregnancy, but during lactation the same amount caused a heavy accumulation of lipid droplets, consisting mainly of cholesterol and/or its esters, triglycerides and very little phospholipid. Persisting CL of pregnancy and cyclic CL seen during lactation and pregnancy, respectively, were unresponsive to exogenous hormones, apparently due to ageing as no lipid changes occurred in the CL after hormonal treatment.

The results are discussed in relation to previous histochemical and biochemical studies and suggest that both $\mathrm{LH}$ and prolactin regulate the lipid and cholesterol metabolism in the luteal cells of the rat.
\end{abstract}

\section{INTRODUCTION}

In previous papers (Guraya, 1972, 1975), a detailed histochemical study was made of lipid changes in the CL of intact rats during the oestrous cycle, pseudopregnancy, pregnancy and lactation. In their amount and histochemical composition, the lipid droplets of CL vary greatly during these reproductive 
states. The cyclic nature of the lipid changes suggests that some hormonal causal factors are concerned, the nature of which is still controversial (Everett, 1947; Zarrow \& Clark, 1969; Armstrong, Knudsen \& Miller, 1970). The present histochemical study was, therefore, undertaken to determine the rôles of exogenous oestradiol benzoate (EB), LH and prolactin alone or in combination in bringing about the lipid changes within the rat CL during the oestrous cycle, pregnancy and lactation. Previous workers have mostly investigated the cholesterol changes in response to exogenous hormonal factors, but, in the present study, the simultaneous alterations in the triglyceride and phospholipid contents of the lipid droplets have been followed, together with the cholesterol changes.

\section{MATERIALS AND METHODS}

Histochemical analysis of lipids in the CL of female Holtzman rats after various treatments with exogenous hormones was carried out during the oestrous cycle, pregnancy and lactation. The rats, weighing 255 to $300 \mathrm{~g}$, were kept in an airconditioned room with a controlled lighting regimen of $14 \mathrm{hr}$ light $/ 10 \mathrm{hr}$ dark. They were maintained on Purina laboratory rat chow supplemented with carrots and water. Vaginal smears were examined each morning. Rats showing regular 4- or 5-day oestrous cycles were used. For the study of the effects of hormones on the lipid changes in the cyclic CL, an attempt was made to use rats with regular 4-day cycles. The pregnant rats were obtained by placing each female with a male of proven fertility on the day of pro-oestrus. On the following morning, the vaginal lavage was checked for the presence of spermatozoa. If they were found, this day was taken as Day 1 of pregnancy. Pregnancy lasted about 22 days. The day of parturition was designated Day 1 of lactation.

The LH and prolactin, which were provided by the Endocrinology Study Section, N.I.H., were injected subcutaneously in $0.1 \mathrm{ml}$ physiological saline, and $\mathrm{EB}$ was administered subcutaneously in $0.1 \mathrm{ml}$ sesame oil. The details of the various experiments and treatments, including the numbers of rats, doses and combinations of hormones, are provided in Table 1 and in the 'Results'.

After the hormonal treatments, the females were killed and their ovaries were processed according to various histochemical methods for lipids and cholesterol and/or esters as described by Guraya (1975). The lipid changes described previously in detail for the CL of normal (or untreated) rats during the oestrous cycle, pregnancy and lactation (Guraya, 1975) constituted the control observations.

\section{RESULTS}

Effects of oestradiol benzoate alone

During the first half of the oestrous cycle and pregnancy, treatment with a single injection of $50 \mu \mathrm{g} \mathrm{EB}$ alone on any day caused a massive accumulation in the GL of lipid droplets which consisted mainly of cholesterol and/or its esters, triglycerides and very few phospholipids (Table 1); the CL of pregnancy stored relatively more cholesterol-positive lipids than those of the oestrous 
cycle. The CL of untreated rats during the corresponding days of the oestrous cycle and pregnancy showed sparsely scattered lipid droplets which consisted mainly of phospholipids and very few triglycerides (Guraya, 1975).

During lactation, two sets of GL, one belonging to pregnancy and the second to lactation, are present. These reacted very differently to treatment with EB. The CL of lactation stored abundant lipid droplets, which consisted mainly of cholesterol and/or its esters, triglycerides and very few phospholipids (Table 1). In the untreated rats, the CL of the corresponding days of lactation contained sparsely scattered lipid droplets, which consisted mainly of phospholipids and very few triglycerides (Guraya, 1975). The pregnancy CL were refractory to treatment with EB and showed no appreciable histochemical change in their lipid droplets (Table 1). The distribution and histochemical reactions of lipid droplets after EB treatment remained the same as those described for the untreated lactating rats (Guraya, 1975). They consisted of phospholipids and triglycerides; no cholesterol and/or its esters were demonstrable. Similarly, the degenerating cyclic $\mathrm{CL}$, which continue to be seen during the first half of pregnancy, were unresponsive to EB treatment as no lipid changes occurred in them.

\section{Effects of oestradiol benzoate combined with prolactin}

When the injection of $50 \mu \mathrm{g} \mathrm{EB}$ was combined with an injection of 15 to 20 i.u. prolactin, the amount of lipid droplets stored in the CL during the first half of the oestrous cycle, pregnancy and lactation was much less than that seen after treatment with EB alone (Table 1). The lipid droplets also contained less cholesterol and/or its esters and triglycerides than the droplets accumulating after EB treatment alone. When prolactin was given as two doses of 10 i.u. twice daily at an interval of 11 to $12 \mathrm{hr}$, Schultz-positive material (cholesterol and/or its esters) did not accumulate in the sparsely distributed lipid droplets (Table 1), and there were fewer triglycerides.

The pregnancy CL during lactation did not show any appreciable lipid change after treatment with EB combined with prolactin. They continued to show lipid droplets consisting of phospholipids and triglycerides (Table 1).

\section{Effects of prolactin alone}

When 20 i.u. prolactin alone was injected daily from Days 8 to 12 of pregnancy, the sparse lipid droplets of CL continued to show the same distribution and histochemical composition as in the untreated rats on the corresponding days (Guraya, 1975). The sparsely distributed lipid droplets consisted of phospholipids and some triglycerides (Table 1). There were no cholesterol and/or its esters, which usually began to accumulate on Day 12 of pregnancy in untreated rats (Guraya, 1975). When 20 i.u. prolactin was injected daily from Day 8 to Day 16 of pregnancy and the rats were killed on Day 17, the CL showed a moderate distribution of lipid droplets which contained relatively small amounts of cholesterol and/or its esters and triglycerides (Table 1). The CL of untreated pregnant rats after Day 12 began to show a heavy accumulation of lipid droplets, consisting mainly of cholesterol and/or its esters, triglycerides and few phospholipids (Guraya, 1975). When the same prolactin treatment 


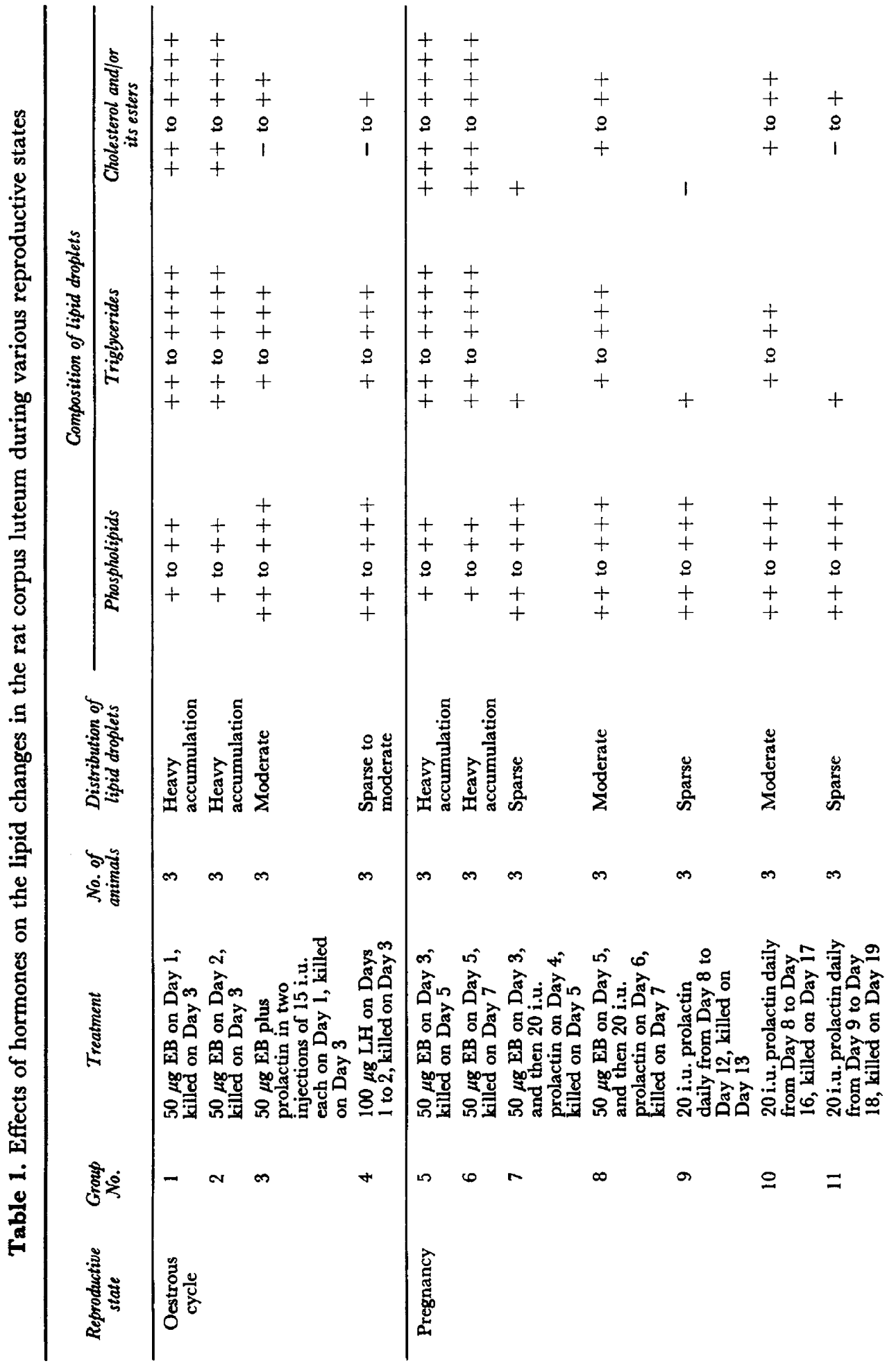


Effects of hormones on lipid changes in $C L$ of rats

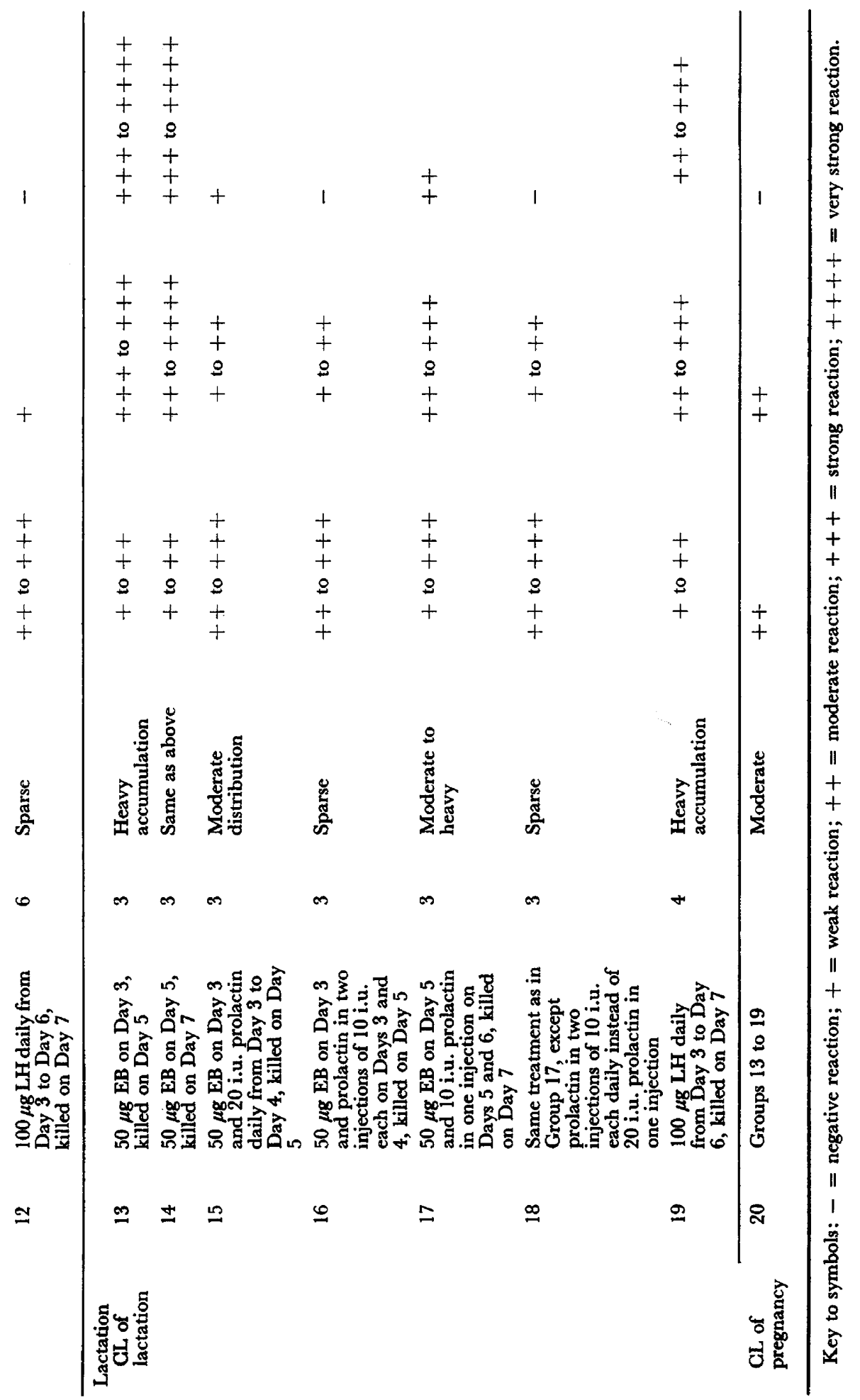


was started on Day 9 and continued to Day 18 of pregnancy, cholesterol and/or its esters either were not developed or their amount was very small as judged from a weak reaction of lipid droplets to the Schultz test (Table 1); the amount of triglycerides stored in the lipid droplets was also decreased compared to that of untreated rats.

\section{Effects of LH alone}

When $100 \mu \mathrm{g} \mathrm{LH}$ was injected daily from Day 1 to Day 2 of the oestrous cycle and the rats were killed on Day 3, the distribution and histochemical nature of the lipid droplets remained the same as that described for the CL of untreated rats (Guraya, 1975). The moderately developed lipid droplets described for the CL in the ovaries of pro-oestrous rats continued to consist of triglycerides, phospholipids and some cholesterol and/or its esters (Table 1). Similarly, $100 \mu \mathrm{g} \mathrm{LH}$ injected daily from Day 3 to Day 6 of pregnancy did not cause any appreciable change in the distribution and histochemistry of the lipid droplets (Table 1). They continued to consist of phospholipids and triglycerides as described for the CL of untreated rats during the corresponding days of pregnancy (Guraya, 1975). By contrast, when $100 \mu \mathrm{g}$ LH was injected daily from Day 3 to Day 6 of lactation and the treated rats were killed on Day 7, the CL of lactation became heavily sudanophilic due to the storage of abundant lipid droplets which consisted mainly of cholesterol and/or its esters, triglycerides and some phospholipids. In the untreated lactating rats, the CL of lactation contained sparsely distributed lipid droplets consisting mainly of phospholipids and some triglycerides (Guraya, 1975). The persisting pregnancy CL remained unresponsive to the treatment as cholesterol and/or its esters did not accumulate.

\section{DISCUSSION}

The diffusely distributed lipoproteins, which presumably derive from the ultrastructural membranes of smooth reticulum (Guraya, 1975), do not show any appreciable change that can be demonstrated with histochemical techniques. The accumulation of lipid droplets in rat CL following injection of EB may be the result either of increased biosynthesis of cholesterol esters and triglycerides by the luteal cells or of an increased uptake of cholesterol and triglycerides from the blood, which are not being utilized for progesterone biosynthesis (Flint \& Armstrong, 1972). Everett (1947) also observed a rich deposition of cholesterol in rat GL during the first half of pregnancy after an injection of $50 \mu \mathrm{g} \mathrm{EB}$. He attributed this to the effect of endogenous $\mathrm{LH}$ released after injection of $\mathrm{EB}$ or after implantation of small oestradiol crystals beneath the skin. He also claimed to have reproduced rich cholesterol storage in the CL of intact or hypophysectomized pregnant rats after treatment with exogenous LH.

These results could not be confirmed in the present study as injection of $100 \mu \mathrm{g} \mathrm{LH}$ did not cause any lipid change (or accumulation of cholesterolpositive lipid droplets) in the CL of intact non-pregnant and pregnant rats. Treatment of hypophysectomized rats with $\mathrm{LH}$ alone or $\mathrm{LH}$ plus prolactin did 
not cause any accumulation of cholesterol-positive lipid droplets in the CL (unpublished observations). Similarly, Zarrow \& Clark (1969) did not observe any cholesterol accumulation in the CL of hypophysectomized rats treated with PMSG and HCG and given LH alone. From this, it appears that the accumulation of cholesterol and/or its esters and triglycerides occurring in CL after treatment of rats with $50 \mu \mathrm{g} \mathrm{EB}$ may not be due to the promotion of hypophysial secretion of $\mathrm{LH}$, but rather to decreased secretion of $\mathrm{LH}$, or prolactin, or both. Divergent opinions have been expressed regarding the effects of oestrogens on the secretion and inhibition of hypophysial gonadotrophins (Allanson \& Parkes, 1966). The accumulation of abundant cholesterolpositive lipid droplets in the luteal cells after treatment with EB suggests that the hypophysial secretion of gonadotrophins ( $\mathrm{LH}$ or prolactin or both) may be inhibited because such droplets usually accumulate in the steroid-producing cells when there are low levels of gonadotrophins (Guraya, 1971, 1973). The LH stimulates steroid (progesterone) biosynthesis by mobilizing intracellular cholesterol (see references in Flint \& Armstrong, 1972).

The effect of $100 \mu \mathrm{g} \mathrm{LH}$ on the CL of lactation, however, was quite different from that on the CL of the oestrous cycle and pregnancy. These differing responses of $\mathrm{CL}$ to $\mathrm{LH}$ suggest that after such treatment, the CL of lactation begin to function by storing hormone precursor (cholesterol and/or its esters) rather than by secreting steroid hormone, which appears to occur effectively in the CL of untreated lactating rats as judged by the absence of cholesterolpositive lipid droplets (Guraya, 1975). The exogenous LH seems to exert an inhibitory effect on steroidogenesis in the GL of lactation by causing accumulation of abundant cholesterol-positive lipid droplets, but does not cause cholesterol accumulation during the first half of the oestrous cycle and pregnancy. The exact cause for these differences in the mode of action of $\mathrm{LH}$ during these various reproductive states could not be determined, but high levels of prolactin discharged during lactation from the pituitary may be responsible for the different responses of the GL of lactation. The injection of $\mathrm{LH}$, which leads to heavy accumulation of cholesterol and/or its esters and triglycerides, seems to cause some change in the $\mathrm{LH}$ : prolactin ratio as these gonadotrophins are now believed to act synergistically in stimulating cholesterol synthesis and progesterone biosynthesis in rat CL (Armstrong, 1968; Armstrong, Miller \& Knudsen, 1969; Armstrong, Knudsen \& Miller, 1970; Flint \& Armstrong, 1972). Armstrong and his co-workers also believe that LH is of less importance for expression of the 'lipogenic' activity than for the 'cholesterogenic' activity of prolactin, though, in the present study, the injection of LH caused a heavy accumulation of lipid droplets in the CL of lactation.

The results of injecting prolactin and EB in the present study suggests that the continuous and prolonged action of prolactin is more effective for not allowing the accumulation of cholesterol and/or its esters and triglycerides to take place. The tonic level of prolactin stimulates progesterone production from the cholesterol because the latter is not available for storage after such a treatment. This is also in agreement with the observation of Everett (1947) who demonstrated that prolactin in some way controls the utilization of this cholesterol. Zarrow \& Clark (1969) observed, however, that prolactin caused a significant 
increase in the accumulation of cholesterol in the CL of hypophysectomized immature rats treated with PMSG and HCG. The accumulation of both free and esterified cholesterol under the influence of prolactin has also been demonstrated by other workers (see references in Flint \& Armstrong, 1972). It is possible that the prolonged effect of exogenous prolactin may affect the hormonal balance in relation to endogenous gonadotrophins (both $\mathrm{LH}$ and prolactin) in such a way that steroidogenesis is stimulated to a degree where not much superfluous cholesterol is available for accumulation. Prolactin alone injected daily from Day 8 to Day 12 of pregnancy did not appear to cause an imbalance in the proportions of endogenous gonadotrophins in the rat, which may lead to the storage of cholesterol- and triglyceride-positive lipid droplets. The steroidogenesis continues effectively during the first half of pregnancy even after daily injections of 20 i.u. prolactin. Such treatment apparently stimulates steroidogenesis during the second half of pregnancy as the heavy accumulation of cholesterol, which occurs in the untreated pregnant rats during this period (Guraya, 1975), is inhibited. This strongly suggests that such an accumulation is the result of decreasing levels of endogenous prolactin in proportion to $\mathrm{LH}$ (Madhwa Raj \& Moudgal, 1970); the rat placenta is believed to secrete two types of hormone, one similar to LH, and the other to prolactin. Prolactin in the rat seems to stimulate steroidogenesis. This is supported by the depletion of cholesterol and/or its esters during the second half of pregnancy in response to exogenous prolactin and the effect of prolactin on the normal response to treatment with EB. These experiments further support the suggestion that the accumulation of cholesterol-positive lipid droplets after injection of EB may be due to inhibition of the hypophysial secretion of prolactin. The present histochemical data on the lipid changes discussed in relation to previous biochemical and histochemical studies lead to the conclusion that both $\mathrm{LH}$ and prolactin act synergistically with each other to regulate the metabolism of cholesteroland triglyceride-containing lipid droplets in the rat CL. This conclusion is supported by the physiological data which have indicated that both LH and prolactin constitute a luteotrophic complex in the rat (see references in Madhwa Raj \& Moudgal, 1970; Hilliard, 1973).

The treatment with various exogenous hormones used here alone or in combination did not cause any lipid change in the persisting pregnancy CL during lactation or in the cyclic CL during pregnancy. This indicates that the CL become unresponsive to exogenous hormones as they age and drastic alterations occur not only in the structural components of the luteal cells but also in the blood supply. The lipid accumulations described for pregnancy CL on Day 12 of lactation in untreated rats (Guraya, 1975) may be due to degenerative changes in the luteal cells. It remains to be determined whether this regression of pregnancy CL also coincides with other events, such as elevation of the content of hydrolytic enzymes and increased content of $20 \alpha$-hydroxysteroid dehydrogenase (Greenwald \& Rothchild, 1968).

\section{REFERENCES}

Allanson, M. \& Parkes, A. S. (1966) Cytological and functional reactions of the hypophysis to gonadal hormones. In Marshall's Physiology of Reproduction, vol. III, Ch. 26, pp. 147-300. Ed. A. S. Parkes. Longmans, London. 
Armstrong, D. T. (1968) Gonadotropins, ovarian metabolism, and steroid biosynthesis. Recent Progr. Horm. Res. 24, 255-319.

Armstrong, D. T., Knudsen, K. A. \& Miller, L. S. (1970) Effects of prolactin upon cholesterol metabolism and progesterone biosynthesis in corpora lutea of rats hypophysectomized during pseudopregnancy. Endocrinology, 86, 634-641.

Armstrong, D. T., Miller, L. S. \& KNudsen, K. A. (1969) Regulation of lipid metabolism and progesterone production in rat corpora lutea and ovarian interstitial elements by prolactin and luteinizing hormone. Endocrinology, 85, 393-401.

Everetr, J. W. (1947) Hormonal factors responsible for deposition of cholesterol in the corpus luteum of the rat. Endocrinology, 41, 364-377.

Fuint, A. P. F. \& ARmstrong, D. T. (1972) Dynamic aspects of ovarian cholesterol metabolism: regulation by gonadotropins. In Gonadotropins, Ch. 22, pp. 269-286. Eds. B. B. Saxena, C. G. Beling and H. M. Gandy. Wiley, New York.

Greenwald, G. S. \& Rothchild, I. (1968) Formation and maintenance of corpora lutea in laboratory animals. F. Anim. Sci. 27, Suppl. 1, 138-162.

Guraya, S. S. (1971) Morphology histochemistry and biochemistry of human ovarian compartments and steroid hormone synthesis. Physiol. Rev. 51, 785-807.

GuRAYA, S. S. (1972) Comparative studies on the histochemical features of ovarian compartments in the rat and golden hamster, with special reference to steroid hormone synthesis. Acta anat. 82, 284304.

Guraya, S. S. (1973) Interstitial gland tissue of mammalian ovary. Acta endocr., Copenh., Suppl. 171, $1-27$.

Guraya, S. S. (1975) Histochemical observations on the lipid changes in the rat corpus luteum during various reproductive states. F. Reprod. Fert. 42, $59-65$.

Hilliard, J. (1973) Corpus luteum function in guinea pigs, hamsters, rats, mice and rabbits. Biol. Reprod. 8, 203-221.

Madhwa Raj, H. G. \& Moudgal, N. R. (1970) Hormonal control of gestation in the intact rat. Endocrinology, 86, 874-889.

ZARRow, M. X. \& CLARK, J. H. (1969) Gonadotropin regulation of ovarian cholesterol levels in the rat. Endocrinology, 84, 340-346. 